\title{
Capítulo I - Definição, epidemiologia, patologia e patogenia
}

\section{Definição}

Asma é uma doença inflamatória crônica caracterizada por hiper-responsividade (HR) das vias aéreas inferiores e por limitação variável ao fluxo aéreo, reversível espontaneamente ou com tratamento, manifestando-se clinicamente por episódios recorrentes de sibilância, dispnéia, aperto no peito e tosse, particularmente à noite e pela manhã ao despertar. Resulta de uma interação entre genética, exposição ambiental e outros fatores específicos que levam ao desenvolvimento e manutenção dos sintomas $^{(1-3)}$.

\section{Epidemiologia}

Anualmente ocorrem cerca de 350.000 internações por asma no Brasil, constituindo-se na quarta causa de hospitalização pelo sus ( $2,3 \%$ do total) e sendo a terceira causa entre crianças e adultos jovens ${ }^{(4)}$. Há registro de aumento desse número de internações entre 1993 e 1999 e indícios de que a prevalência da asma esteja aumentando em todo o mundo, inclusive no Brasil(5,6). Em 1996, os custos do sus com internação por asma foram de 76 milhões de reais, $2,8 \%$ do gasto total anual e o terceiro maior valor gasto com uma doença. Estudo multicêntrico (International Study for Asthma and Allergies in Childhood - ISAAC) realizado em 56 países mostrou uma variabilidade de asma ativa de $1,6 \%$ a $36,8 \%$, estando o Brasil em 8 o lugar, com uma prevalência média de $20 \%{ }^{(7)}$.

A mortalidade por asma ainda é baixa, mas apresenta uma magnitude crescente em diversos países e regiões. Nos países em desenvolvimento, a mortalidade por asma vem aumentando nos últimos 10 anos, correspondendo a $5-10 \%$ das mortes por causa respiratória, com elevada proporção de óbitos domiciliares ${ }^{(8,9)}$.

\section{Patologia e patogenia}

A inflamação brônquica constitui o mais importante fator fisiopatogênico da asma. É resultante de interações complexas entre células inflamatórias, mediadores e células estruturais das vias aéreas ${ }^{(3,10,11)}$. Está presente em pacientes com asma de início recente, em pacientes com formas leves da doença e mesmo entre os assintomáti$\cos ^{(12,13)}$.

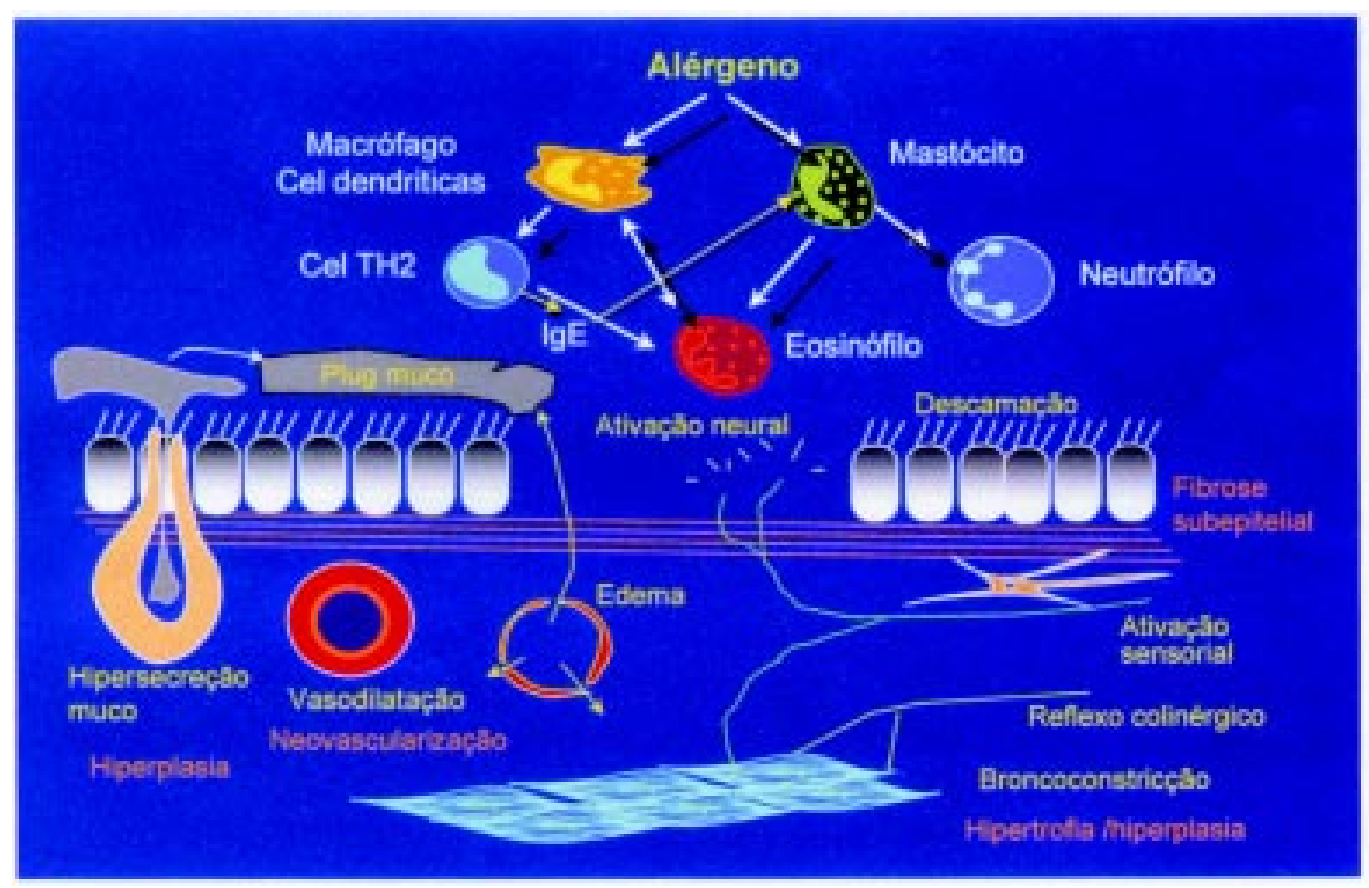

Figura 1 - As complexas interações celulares, neurais presentes na patogenia da asma resultam em manutenção da inflamação e conduzem ao remodelamento brônquico 
A resposta inflamatória tem características especiais que incluem infiltração eosinofílica, degranulação de mastócitos, lesão intersticial das paredes das vias aéreas e ativação de linfócitos Th2 que produzem citocinas, como as interleucinas IL-4, IL-5, IL-13, entre outras, responsáveis pelo início e manutenção do processo inflamatório. A IL4 tem papel importante no aumento tanto da produção de IgE específica como da expressão de receptores de alta e baixa afinidade à IgE por muitas células inflamatórias $^{(14,15)}$.

Vários mediadores inflamatórios são liberados pelos mastócitos brônquicos (histamina, leucotrienos, triptase e prostaglandinas), pelos macrófagos (fator de necrose tumoral - TNF $\alpha, \mathrm{IL}-6$, óxido nítrico), pelos linfócitos T (IL-2, IL-3, IL-4, IL-5, fator alfa de crescimento de colônia de granulócitos (GM-CSF), pelos eosinófilos (MBP, ECP, EPO, mediadores lipídicos e citocinas), pelos neutrófilos (elastase) e pelas células epiteliais (endotelina-1, mediadores lipídicos, óxido nítrico). Através de seus mediadores as células causam lesões e alterações na integridade epitelial, anor-

\section{Referên Cias}

1. Busse WW, Lemanske RF. Asthma. N Engl J Med 2001;344:350-62.

2. Cookson $W$. The alliance of genes and environment in asthma and allergy. Nature 1999;402(Suppl):B5-B11.

3. Kumar RK. Understanding airway wall remodeling in asthma: a basis for improvements in therapy. Pharmacol Ther 2001;91:93-104.

4. Ministério da Saúde. Secretaria Nacional de Ações Básicas de Saúde, Estatísticas de Mortalidade, 2000.

5. Fiori R, Fristcher $C C$. Variação na prevalência de asma e atopia em um grupo de escolares de Porto Alegre/RS. J Pneumol 2001;27:23742.

6. Gergen PJ, Mullally DI, Evans Richard. National survey of prevalence of asthma among children in the United States, 1976 to 1980 . Pediatrics 1988;88:1-7.

7. The International Study of Asthma and Allergy in Childhood (ISSAC) Steering Committee. Worldwide variation in prevalence of asthma symptoms: The International Study of Asthma and Allergy in Childhood (ISSAC). Eur Respir J 1998;12:315-35.

8. Chatkin J M, Menna Barreto S, Fonseca N. Trends in asthma mortality in young people in Southern Brazil. Ann Allergy Asthma Imunnol 1999; 82:287-92.

9. Weiss KB, Wagener DK. Changing patterns of asthma mortality. J AMA 1990;264:1683-7. malidades no controle neural autonômico (substância $P$, neurocinina $A$ ) e no tônus da via aérea, alterações na permeabilidade vascular, hipersecreção de muco, mudanças na função mucociliar e aumento da reatividade do músculo liso da via aérea(3,16,17).

Esses mediadores podem ainda atingir o epitélio ciliado, causando-Ihe dano e ruptura. Como conseqüência, células epiteliais e miofibroblastos, presentes abaixo do epitélio, proliferam e iniciam o depósito intersticial de colágeno na lâmina reticular da membrana basal, o que explica o aparente espessamento da membrana basal e as lesões irreversíveis que podem ocorrer em alguns pacientes com asma. Outras alterações, incluindo hipertrofia e hiperplasia do músculo liso, elevação no número de células caliciformes, aumento das glândulas submucosas e alteração no depósito/degradação dos componentes da matriz extracelular, são constituintes do remodelamento que interfere na arquitetura da via aérea, levando à irreversibilidade de obstrução que se observa em alguns pacientes $^{(3)}$ (Figura 1).

10. Barnes PJ, Grunstein MM, Leff AR. Asthma. Philadelphia: LippincottRaven, 1997;2183p.

11. Djukanovic R, Wilson JW, Britten KM, Wilson SJ, Walls AF, Roche WR, et al. Quantitation of mast cells and eosinophils in the bronchial mucosa of symptomatic atopic asthmatics and healthy control subjects using immunohistochemistry. Am Rev Respir Dis 1990;142:863-71.

12. Louis R, Lau LC, Bron AO, Roldaan AC, Radernecker M, Djukonovic $R$. The relationship between airways inflammation and asthma severity [abstract]. Am J Respir Crit Care Med 2000;161:9-16.

13. Vignola AM, Chanez P, Campbell AM, Souques F, Lebel B, Enander I, et al. Airway inflammation in mild intermittent and in persistent asthma. Am J Respir Crit Care Med 1998;157:403-9.

14. Bousquet J, Chanez P, Lacoste JY, Barneon G, Ghavanian N, Enander I. Eosinophilic inflammation in asthma. N Engl J Med 1990;323:103339.

15. Robinson DS, Hamid Q, Ying S, Tsicopoulos A, Barkans J, Bentley AM, et al. Predominant Th2-like bronchoalveolar T-lymphocyte population in atopic asthma. N Engl J Med 1992;326:298-304.

16. Holgate ST. Asthma: a dynamic disease of inflammation and repair. In: The rising trends in asthma, 1997;206:p.5.

17. Holgate ST. Inflammatory and structural changes in the airways of patients with asthma. Respir Med 2000;94(Suppl D):S3-6. 